\title{
Mindfulness and Sufficiency Economy: Framework for Waste Management Reform
}

\author{
Chainarong Khaw-ngern \\ Faculty of Humanities, Mahachulalongkornrajavidyalaya University \\ chainarong.kha@mcu.ac.th
}

\begin{abstract}
Due to increase in population, economic expansion, growth and expansion of the city, more waste problems are increasing and becoming a global problem that every country encounters. Only waste management policies from government and waste management campaigns from private sectors cannot keep up with the excessive waste amount unless all people in societies become aware that their cooperation in waste reduction can make a great contribution. This paper provides an overview of waste management in Thailand, how private sectors take part in waste management, and how consumers in communities can contribute in waste reduction. It also suggests the framework of mindfulness and Sufficiency Economy Philosophy for waste management reform. Documentary study and literature review were used for data collection. The results showed that consumers can be a big producer of waste due to their overconsumption behavior, so they can take the major role in waste reduction with moderate consumption. Mindfulness can conduct consumers to stay awake and aware of waste problems and have a sense of caring towards other people, their communities and environment. Sufficiency Economy philosophy can work as a guideline for consumers to make ethical choice with moderation, reasonableness, and prudence. With the framework of mindfulness and sufficiency economy philosophy, waste management reform can be conducted at the beginning stage for waste reduction before it is generated. With the care of environment and their communities, consumers will be willing to work together with government and private sectors in following 3R (Reduce, Reuse, Recycle) concept for sustainability.
\end{abstract}

Keywords

Waste manage reform, Moderate consumption, Waste reduction, Mindfulness, Sufficiency Economy Philosophy

Article Received: 10 August 2020, Revised: 25 October 2020, Accepted: 18 November 2020

\section{Introduction}

In Thailand the amount of municipal solid waste generated in 2018 was at 27.8 million tons, which is a $1.64 \%$ increase from 2017 due to expanding urban communities, and lifestyle changing from the shift of an agricultural to an urban society. Moreover, population growth, tourism promotion and higher consumption are also the factors that cause higher amounts of solid waste in various areas [1]. There are still many problems and obstacles that we should consider in order to correct and develop waste management to dispose waste efficiently in various areas nationwide and with best value for money as well as to reduce the impact that will cause injury to the public and damage to environment of the country.

Why a garbage crisis has struck and how can waste management be reformed? The waste management reform must be carried out in steps in order to educate local people, companies, manufacturers and other stakeholders to be aware of waste problems and to take part in waste management, to motivate them for serious collaboration as well as to establish waste management models for demonstrating effective management. In addition, the consumer behavior has to be changed so they can consumer moderately, knowledgeably, and rationally in order to reduce the problem of waste at source and to enable communities, regions, and governments to be successful in sustainable waste solutions.

Right mindfulness and Philosophy of Sufficiency Economy can be introduced as effective framework for waste management. Philosophy of Sufficiency Economy emphasizes that the producers or consumers try to produce or consume within the limitation of existing income or resources first while right mindfulness keeps them to go on track. This is an important principle in decreasing the requirement for unnecessary things, reducing waste generation, and increasing the ability to control the production. Right mindfulness and Sufficiency Economy principles and activities must be carried out at a sufficient level along with emphasizing on knowledge and virtue conditions. This framework underpinned by knowledge and morality could lead us to practical waste management reform and further sustainable waste management.

\section{Solid Waste And Waste Management In Thailand}

The Resource Conservation and Recovery Act (RCRA) of America states that "solid waste" means any garbage or refuse, sludge from a wastewater treatment plant, water supply treatment plant, or air pollution control facility and other discarded material, resulting from industrial, commercial, mining, and agricultural operations, and from community activities. Nearly everything we do leaves behind some kind of waste. People need to know that solid waste does not mean only physically sold substance Many solid wastes are liquid, semi-solid, or contained gaseous material [2].

For Thailand, solid waste is a waste type consisting of everyday items that are discarded by the public including organic waste, plastic waste, industrial and toxic waste, medical waste, and electronic waste. Thais per capita generate an estimated $1.14 \mathrm{~kg}$ of solid waste per dayabout 50 percent of it biodegradable. According to Interior 
Ministry statistics, refuse nationwide in 2016 amounted to 27 million tonnes, up about 0.7 percent from the previous year [3].

In Thailand the roles in solid waste management (MSW) and industrial waste management are organized by the Royal Thai Government, which is divided among the central government, regional governments, and local governments. Each government is responsible for different tasks. The responsibility for stimulating regulation, policies, and standards belongs to the central government while the regional governments are taking care of coordinating central and local governments. Local governments are in charge of waste management in their governed area. However, local governments themselves do not handle waste disposal, they hire private companies that have been granted that right by the Pollution Control Department (PCD) [4].

\section{Waste Management Reform}

Open-air dumps, an absence of street litter bins, an impractical waste recycling system and abundant overuse of plastic grocery bags are all evidence that Thailand has a huge waste and waste management problems. There are many standpoints we can analyze this problem from. To start, Thai people are not well educated on what recycling is and how they can do proper waste sorting. Lots of them don't even know how an individual's actions can make a difference. Just very few Thais realize that there are no dead batteries disposals, and the vast majority is never concerned at all that throwing everything in the same bin can cause harm to the environment.

Besides lack of knowledge about waste sorting and the inappropriate waste disposal by people in communities, consumption behavior is also one major factor of increasing municipal solid waste. According to the World Bank report [5], it is estimated that the world will generate solid waste about 1.2 per capita and the amount is expected to reach 1.5 kgs. by 2025 . That means every country will suffer from excessive amount of waste. The actual cause of the problem is that companies and producers have been trying to increase their sales and profits by supplying single-use products without prioritizing on reuse, recycling or the use of environmentally friendly materials [6].

Waste management reform is considered an urgency for Thailand in order to limit the amount of waste not exceeding the disposal capacity of the communities, both private and public sectors. Recycling is considered one of the most effective tools of waste management in our country. However, many communities still do not have enough facilities and they do not know how to collect, sort, and transport waste properly. That could be major obstacles for waste management. Thus, leading businesses in private sectors and government are required to work together in order to provide effective tools and equipment for the communities and educate the people about proper waste management.

\section{Management Of Waste For Recycling}

The appropriate and effective waste collection and management is to have it re-enter the recycling process at best possible. To be successful in waste management, there must be changes in behavior and management system which include efficient facility for effective waste collection, proper procedures in waste sorting and transporting, and reduction of contaminated waste to the minimum. For example, the PTT Global Chemical company collaborates with the governments, private sectors and communities in better waste management and promote the use of plastics sustainably. Besides the goal to reduce the quantity of plastic waste in Thai seas at least $50 \%$ within 2027, the company put efforts to reduce plastic wastes by using more biodegradable plastics and following the circular economy concepts of reuse, recycle, and recovery. They promote the development of reusable plastic products and transform plastic wastes into new products. In 2019, 300 tons of waste are recycled throughout the project implementation. More income, over 3.5 million baht, also can be generated in Rayong communities [7].

In addition, Khung BangKachao Model is a collaboration among 34 organizations from the governments, private sectors and civil sectors under the supervision of Chaipattana Foundation. Khung BangKachao Model aims to develop a green area and elevate the quality of life in community while developing the area to grow strongly and become a sustainable eco-friendly community model. PTT GC has implemented the principles of circular economy to reduce waste problems as well as raise awareness in waste management from original source. An outstanding project in 2019 is the development of recycled monk robes. This project uses Polyethylene Terephthalate (PET) bottle recycling innovation to manufacture polyester threads. With the combination of polyester zinc and cotton, the strands are woven for fabric and made into monk robes. Besides transforming the used PET bottles in to value-added products, the project has also created jobs and brought more income to the community [8].

The Siam Cement Group has made efforts with the launch of "Bangsue Model" to encourage employees in the office at Bangsue and affiliated factories nationwide to change their behaviors in alignment with "Resource MaximizationCorrect Sorting-Proper Disposal" concept. With the finding that correct waste sorting is the first stage for waste management, SCG has designed 6-color bins for easy-tounderstand and for sorting waste of different material. Bangsue Model can be an outstanding example of proper waste sorting and it can decrease the amount of total waste steadily from month to month. Sorted waste, then, has been increasingly recycled and properly managed. Paper and plastic waste have been recycled. Waste from food scraps is composted as soil improvement substances for planting. SCG target at reducing the amount of waste sent to landfill to zero (Zero Waste to Landfill) by the year 2021 [9].

Moreover, the "ThinkCycle Bank" project of PTT GC is also another initiation to transform waste into valuable materials in the economy. The project uses online recycling bank to handle the waste problems at its source. Thus, it can promote understanding on waste separation and waste reuse according to the Circular Economy, while creating a network for waste separation from households to provincial level. The project can promote awareness of waste and waste problems in youth communities and guide them how to manage waste and maximize its benefits as well as 
provide more jobs and incomes from recycling wastes. In $2019,12,581$ tons of wasted were recycled [10].

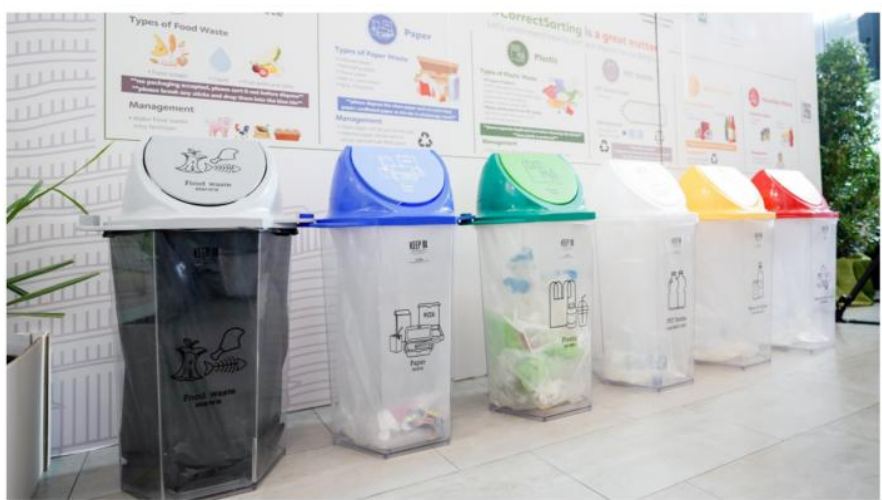

Figure 1. Garbage bins in 6 different colors for waste segregation [11]

Garbage bank can be considered as an example of how to manage waste and how to turn waste into income as it buys back sorted waste from the members and send them to recycling process in factories. However, it needs to integrate technology to keep the record updated as now they record transaction in notebook which cause difficulties and delay in the process. Therefore, SCG develops "KoomKah" application on mobile phone to get the waste management more systematical and effective as it can record amount and type of the waste, inform buying and selling prices, even assist in trading and transportation plan. The application provides more opportunities to distribute garbage to recycling factory and power generation plant from waste. Currently, Koomkah application has been used by 23 communities' garbage banks [12].

For an Approach to Waste Recycling Collaboration, SCG realizes that to enhance waste collection to be successful in accordance with Circular Economy principle requires the involvement from a number of sectors outside the organization. SCG, therefore, steps up the effort to develop project and innovation as a tool. An example is with regards to the development of PaperX Digital platform to provide service in buying back the wastepaper and returning them to the recycling process through PaperX application. Another example of cooperation is Siam Fiberglass company, the producer of insulation glass wool, introduced the insulator waste as the new material for new insulation glass wool production. The project increases the use of recycled materials by $4 \%$ and decreases the amount of disposal waste from the customers for more than 435 tons per year. Besides, Siam Fiberglass Co., Ltd. processed Post Consumed Glass Cullet as substitute raw materials for Silica Sand, which can reduce consumption of natural resources by 10,500 tons per year [13].

Although cities are the large sources of waste, especially plastic waste, they are positioned to achieve waste management in the near future. If there is a practical national framework, cities will be able to design education and incentive programs that promote culture of recycling, and set up regulatory framework for recycling as well as start pilot projects for proper collecting and sorting which will make recycling process efficient and easy to access. It requires Integrated programs to reach the full potential of plastic-waste management. What they have learned from previous practices can be used as information for developing the best practices for easy sharing and repetition. Waste management can be a critical issue for the plastics industry for many years from now. As a result, the plastics industry is at a crossroads and now is the time to act.

In Thailand, waste is classified into municipality solid waste, industrial hazardous waste, infectious waste, plastic waste, and e-waste. The basic laws for waste management in Thailand are related to municipality, public health, environmental quality and conservation, and decentralization. Thailand generates a large amount of municipal waste, at about 27 million tons per year. MSW generation per capita per day in Thailand is $1.05 \mathrm{~kg}$ as of 2016, which comes in fourth place among ASEAN countries after Singapore, Brunei and Malaysia [14].

The amount of annual MSW generated is increasing every year. Out of 26,850,000 total tons of MSW in Thailand, $76.23 \%$ is collected in collection areas (20,470,000 tons), $17.65 \%$ is recycled, and $31.06 \%$ is properly treated, while $26.63 \%$ is improperly treated $(8,340,000$ tons $)$. Of the $31.06 \%$ of MSW properly 8 treated, $25.66 \%$ goes to landfills, $1.52 \%$ is incinerated, while only $1.82 \%$ is composted. The composition of MSW is mostly (1) Food/Organic waste 64\%, (2) Paper 8\%, (3) Plastic 17.6\% and (4) Metal 2\% [15].

Thai government together with private companies and Thai people aim to turn Thailand into a zero-waste society in order to solve waste problems. Department of Environment Quality Promotion has produced a 'Mission Zero Waste' educational booklet to be used in schools. The book contains helpful suggestions for the youth how they can reduce, reuse, and recycle their waste. The book also introduced a 'Zero Waste Community' award for villages that are able to significantly reduce the amount of waste that they produce. The response is quite appreciated; in 2017 over 700 villages entered the competition, which was won by two villages in Buriram Province in the country's northeast [16]. In order to reduce their waste, the villagers separated and recycled all their plastic, paper and glass, and transformed their organic waste into fermented fertilizer and organic pesticides to replace chemical products on local farms. In this way, villagers not only live healthier lives, but they make money from their waste.

Mission Zero Waste, waste recycling project, correct waste sorting, and recycling bank are the cooperation between government and private sectors in regards to waste management and these programs are all the actions after waste generation. However, there seems to be no mention of reducing excessive consumption or promoting the framework of moderate consumption with mindfulness. Mindfulness and moderation can help consumers make their choice of consumption in a right manner which responds to their needs and does not cause harm to communities and environment.

\section{Mindfulness And Sufficiency Economy Philosophy}


Economics says demand $\rightarrow$ consumption $\rightarrow$ satisfaction, and

that's the end of it, there's no need to know what happens afterwards. In this view consumption can be of anything whatsoever so long as it results in satisfaction. Economics does not consider if human well-being is negatively affected by that consumption. Buddhism agrees with the basic concept of consumption but adds that human well-being must be augmented by the satisfaction of a demand. Consumption must improve quality of life as its aim. This is the difference of perspective [17].

According to economic perspective, ones becomes satisfy when their desires have been fulfilled or their requirements have been served. What if their desires are higher than the amount they really need? The surplus of their need can become waste. Some visible examples are people order more food than what they really need for a meal, buy more clothes than what they really need for their living and working, and purchase more electronic gadgets than what they really want to perform their jobs and daily routines. The excessive quantity of food, clothes, and gadgets can be considered as waste. Can excessive consumption be considered as a major factor of waste generation? The answer is 'yes'. Thus, moderate consumption should be considered as the initial stage of waste management reform.

Right mindfulness is one of the principles in Buddhist Nobel Eightfold Path. mindfulness, sati, is interpreted as never be absent minded, being conscious of what one is doing. This encourages the awareness of one's action in every moment. Mindfulness can be likened to a state of "natural, uncontrived, spontaneously arisen awareness that is inseparable from every moment of experience" [18]. Consumption with mindfulness can help consumer stay aware of the choice they are making, what they buy, what they eat, what they do, and being considerate of other people, communities, and environment. Right mindfulness can guide an individual to right direction and go on a more sustainable way. Right mindfulness can strengthen waste management reform in term of guiding individuals to keep going in moderate consumption.

Another conceptual framework that can be effective for waste management regarding moderate consumption is the Principles of Sufficiency Economy, the principles initiated by H.M. King Bhumibol Adulyadej over 30 years ago for guidance on development stressing the modest practices and conscientiousness in all modes of conduct. Principles of Sufficiency Economy is a guidance of how people can lead their lives with moderation, reasonableness, and prudence on the basis of knowledge and virtue. It also encompasses wisdom and perseverance which will enable people to live a truly harmonious and happy life. Two conditions in the principle are Knowledge and Virtues. Knowledge relates to academic approaches and the ability to integrate and knowledge in planning and implementation prudently and carefully. Virtues adheres to ethics, integrity, patience, perseverance, and living life intelligently. Sufficiency Economy principle also includes three principles; Moderation, Reasonableness and Prudence. Moderation means the sense of not too much or not too little and being moderate without exploiting oneself or others. Reasonableness, the choice of sufficiency level should be justifiable by carefully taking into consideration all the relevant factors and consequences that may ensue as a result. Prudence means preparing for and conducting oneself to cope with the impacts and changes through the anticipation of the situations that may happen in the future [19].

The philosophy of the Sufficiency Economy guides the people to a balanced way of life and to be the main sustainable development theory for the future. The theory is based upon a Middle Path between society at the local level and the market in the global context. By highlighting a balanced approach, the philosophy allows the nation to modernize without resisting globalization but provides a means to counteract negative outcomes from rapid economic and cultural transitions [20]. The Sufficiency Economy became critical during the economic crisis in 1997, in which Thailand needed to maintain stability to persist on selfreliance and develop important policies to recover. By creating a self-supporting economy, Thai citizens will have what they need to survive but not excess, which would turn into waste. This can be applied to the individual level, the community level and the national level.

It is important to strengthen the morality of people in the nation, so that everyone, particularly public officials, businessmen, academics, even consumers, carries their roles within the principles of honesty and integrity. In addition, with patience, perseverance, diligence, wisdom and prudence in their way of life helps them create balance and be able to cope appropriately with critical challenges arising from rapid socioeconomic, environmental, and cultural changes in the world.

The sufficiency economy philosophy is considered a new paradigm for development and aims to improve human wellbeing as well as providing a balanced way of living to people. Immunity to environment changes prompts individuals and their communities to be aware of the impacts their actions and consumptions may have on the environment, and subsequently their livelihoods. That is an awareness leading them to live in harmony with nature. In order to construct effective waste management, it is important to help practitioners realize the real value in the practice. Mainstream consumption, leading to consumerism may cause internal and external shocks. In contrast, consumption with reasonableness and with consideration in all modes of conduct could prevent the long-term impacts on society and environment. To achieve this, the application of consciousness and knowledge with prudence should be kept in mind of everyone in every society. Rules and regulations could not be built alone, unless the actions of practice are initiated and developed. It was also important to evaluate those practices by following up the actions. Unnecessary or useless practices must be replaced with a more practical one. (Figure 2) 


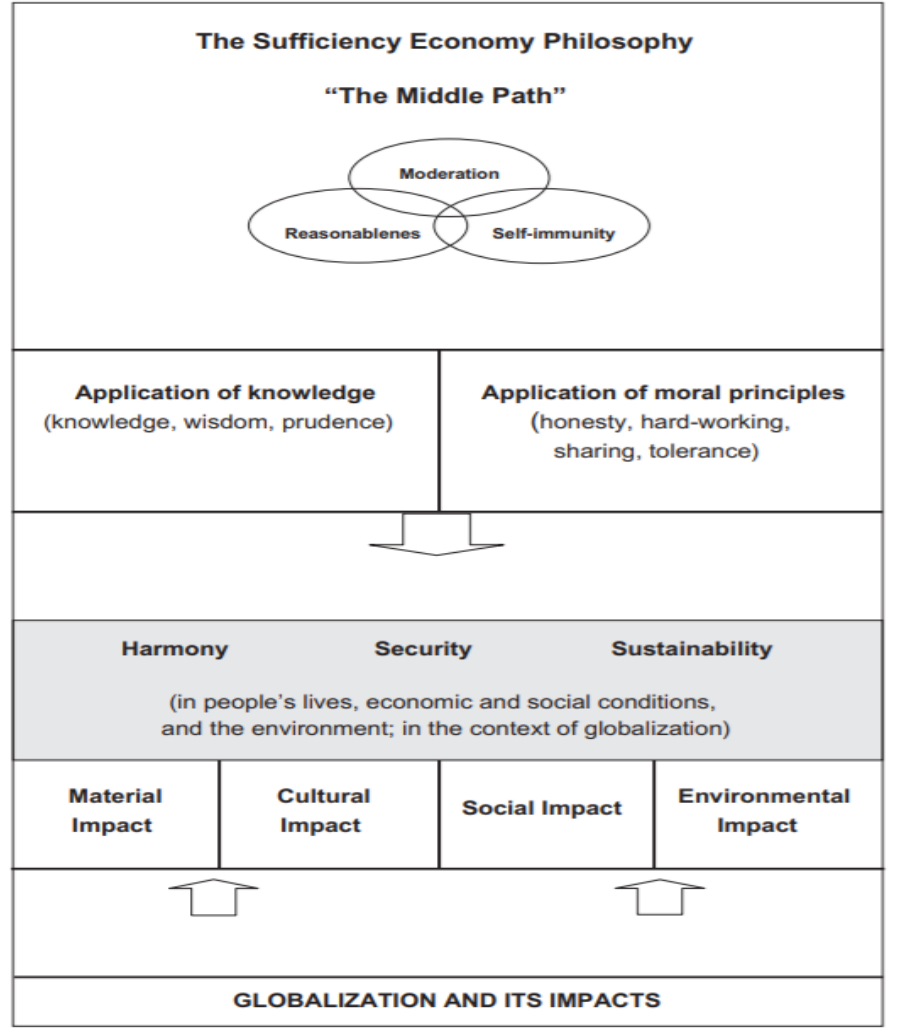

Figure 2. The philosophy of sufficiency economy framework [21]
With the framework of right mindfulness and sufficiency economy, waste management can be operated more effectively because the process starts from reduction of waste generation. People and communities can work together in managing their waste properly according to $3 \mathrm{R}$ (Reduce, Reuse, Recycle) since they stay aware of waste problems, have knowledge about waste pollutions and its harm to themselves and their communities, and retain good care about the environment. (Figure 3)

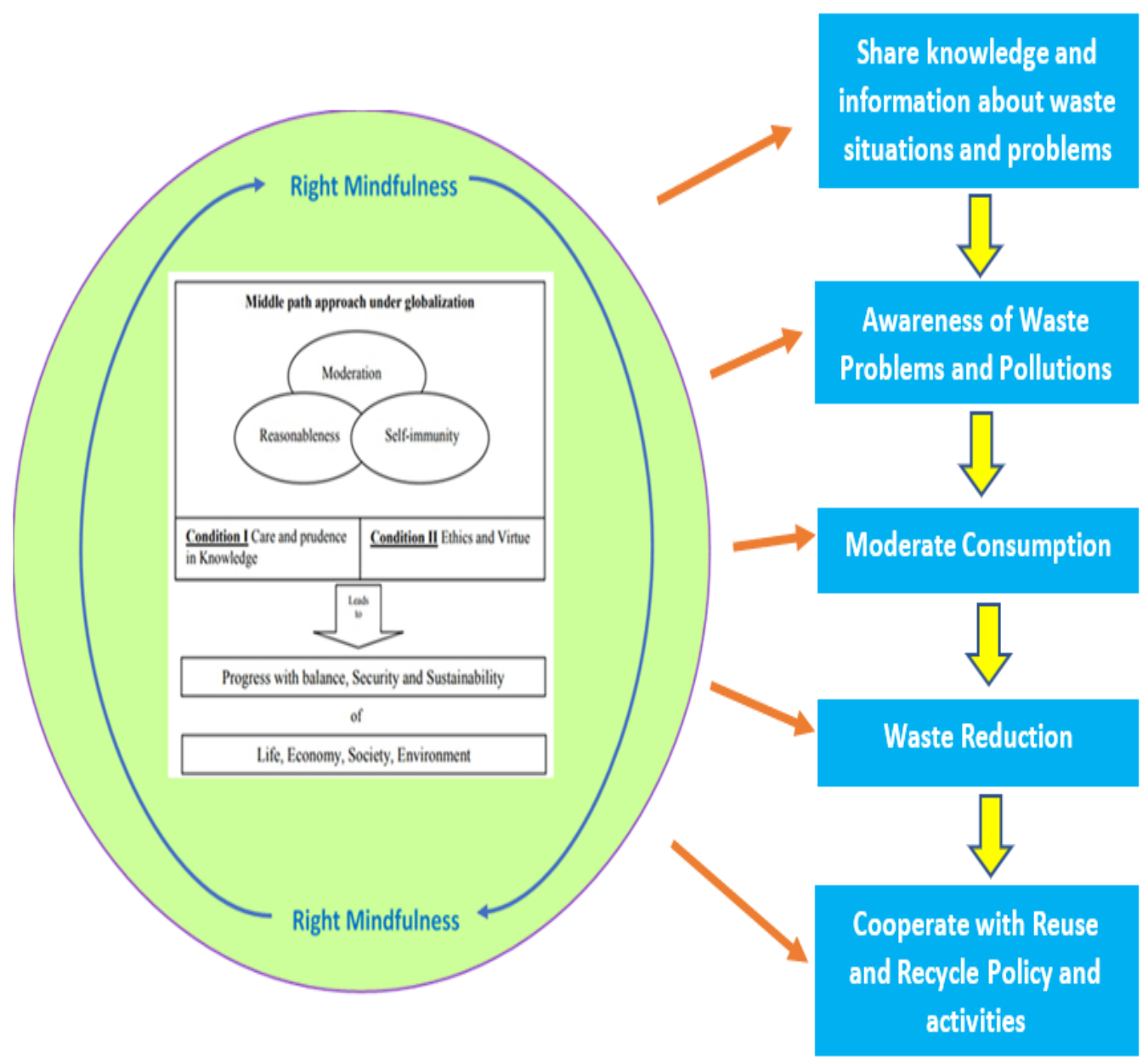

Figure 3. Right Mindfulness and Sufficiency Economy Framework for Waste Management 
Moreover, we can establish a robust regulatory environment to support the sustainable operation of the waste and resource recovery industry by following the sufficiency economy philosophy which guides to a balanced way of life and to be the main sustainable development theory for the future. In addition, a way of life based on patience, perseverance, diligence, wisdom and prudence can help us create balance and enable us cope appropriately with critical challenges arising from rapid socioeconomic and environmental changes. In order to succeed in waste management, it requires the change in behavior and management system, right facility for efficient collection of waste, proper procedures in waste sorting and transporting. The concept of gaining currency in waste policy is one of motives in the circular economy, which envisages keeping products, components, and materials at their highest utility and value at all times [22]. Right mindfulness and sufficiency economy philosophy can strengthen waste management reform efficiently.

\section{Conclusion}

Consumers in the era of globalization and economic integration are having more access to more products and services. Also, rapid urbanization, increase in population, higher income and consumption inevitably lead to mass generation of waste. In order to achieve sustainable development, a paradigm shift is needed from reactive policies to more preventive policies. In a scenario where technology matures, the "ThinkCycle Bank" in one of practical projects in order to transform waste into valuable materials in the economy by using the online recycling bank. PTT GC has put its efforts to solve the waste problem at its source and promotes understanding on waste separation and waste reusing. Moreover, Garbage bank is considered a mechanism in the cycle of circular economy through the buying back of sorted waste from the members and passing them on to the recycling process of the factories. ThinkCycle Bank and Garbage Bank are model to increases the opportunity to distribute garbage to recycling factory and power generation plant from waste. Furthermore, The Siam Cement Group has launch of "Bangsue Model" to encourage employees in the office and affiliated factories nationwide to change their behaviors in alignment with "Resource Maximization - Correct SortingProper Disposal" concept. With the finding that correct waste sorting is the first stage for waste management, SCG has designed 6-color bins to respond the finding. In addition, Khung BangKachao model aims to develop a green area and elevate the quality of life in community by developing the area to grow strongly and become a sustainable eco-friendly community model. The main activities of the associations are that they carry out information and educational activities to raise awareness of individuals and legal entities about the importance of waste disposal, and to educate legal entities in the treatment of waste. In order to achieve sustainable development, the reactive policies need to be changed towards more preventive policies. In this paper we have addressed the Right Mindfulness and Philosophy of "Sufficiency Economy" as a practical framework for waste management reform at the initial stage which will contribute to awareness of waste problems, moderate consumption, waste reduction, and cooperation with $3 \mathrm{R}$ (Reduce, Reuse, Recycle) policy. This framework underpinned by knowledge and morality can lead us to effective waste management reform and to sustainability.

\section{References}

[1] Pollution Control Department. (2019). Booklet on Thailand State of Pollution 2018. Bangkok: S.Mongkon Press.

[2] https://www.epa.gov/hw/criteriadefinition-solid-waste-and-solid-andhazardous-waste-exclusions

[3] https://www.bangkokpost.com/thailand/ge neral/1376235/suttipong-told-to-clean-upor-else

[4] Jiaranaikhajorn, Taweechai. "Waste and Hazardous Substances Management Bureau" (PDF). Pollution Control Department (PCD). Retrieved 22 November 2014.

[5] World Bank. (2018). Global Waste to Grow by 70 Percent by 2050 Unless Urgent Action is Taken: World Bank Report. Retrieved 27 July 2020 from https://www.worldbank.Org/ en/news/press-release/2018/09/20/globalwaste-to-grow-by-70-percent-by-2050unless-urgent-action-is-taken-world-bankreport.

[6] https://www.conserve-energyfuture.com/various-waste-disposalproblems-and-solutions.php

[7] PTT Global Chemical. (2019). Circular Economy. Retrieved 29 July 2020 from https://www. pttgcgroup.com/en/sustainability/circulareconomy

[8] The Siam Cement. (2020). Sustainability Highlights 2019. Retrieved 29 July 2020 from https: //scc.listedcompany.com/misc/sustainabilit y_report/20200302-scc-sdr-2019-en01.pdf

[9] https://www.allaroundplastics.com/article/ sustainability/2585

[10] Funatsu, T. (2019). Municipal Solid Waste Management in Thai Local Governments: 
The State of the problem and prospects for regional waste management, ERIA Collaborative/Support Research Report "Toward Regional Cooperation of Local Governments in ASEAN". IDE-JETRO. Retrieved 27 July 2020 from https://www.ide.go.

jp/library/English/Publish/Download/Ec/p df/201903_ch04.pdf

[11] United Nations Environment Program. (2017) Waste Management in Asean Countries: Summary Report. Bangkok: UNEP.

[12] Tourism Authority of Thailand (2018). Thailand Aims for Zero Waste. Retrieved 29 July 2020 from https://7greens.tourismthailand.org/greencontent/thailand-aims-for-zero-waste/

[13] P. A. Payutto, 2016, Buddhist Economics, p. 22

[14] Kang, C., \& Whittingham, K. (2010). Mindfulness: a dialogue between Buddhism and clinical psychology. Mindfulness, 1, 161-173.

[15] Arundeea, S. and Thiphoom, S. (2015). The solid waste management according to sufficiency economy philosophy of the personal characteristics at Phra-YotMueangy Fort, Nakhon Phaom province, Thailand. Procedia Social and Behavioral Sciences 197 ( 2015 ) 1107 - 1112.

[16] Kansuntisukmongkol, K. (2017). Philosophy of sufficiency economy for community-based adaptation to climate change: Lessons learned from Thai casestudies. Kasetsart Journal of Social Sciences. 38 (2017) 56-61.

[17] https://www.unescap.org/sites/default/files /apdj-17-1-5-Mongsawad.pdf

[18] Saif, Y. \& et al. (2017). A circular economy solid waste supply chain management based approach under uncertainty. Energy Procedia. 142 (2017) 2971-2976. 